\title{
Arroz, feijão, saúde, educação: Política Pública de Saúde no Brasil
}

Políticas públicas de saúde são, na essência, políticas intersetoriais. A crise financeira, reconhecida na arena internacional em 2008 e agravada pela escassez de alimentos, pela crise energética e pelo aquecimento global, reiteram antigos problemas e apresentam novos desafios, em grau e complexidade crescentes. Não há, hoje, nação capaz de garantir cuidados à saúde de todos os seus cidadãos e enfrentar seus determinantes sem uma audaciosa integração entre setores governamentais.

No Brasil, a perspectiva de mobilidade social, associada a políticas de distribuição da riqueza, de geração de emprego e renda, sugere um cenário que desafia o antigo paradoxo: crescimento econômico e desenvolvimento social. Como estabelecer uma política de saúde que responda aos valores da Constituição Brasileira e da Lei Orgânica da Saúde em situações em que uma parcela significativa da população ainda subsiste abaixo da linha da pobreza? Como assegurar boas políticas de Saúde e Educação - classificadas internacionalmente como low politics, em contraponto com a segurança e os gastos militares, high politics - quando, em situações de contenção orçamentária, são aquelas as primeiras a sofrerem cortes?

No âmbito do setor Saúde no país, a expansão do acesso à atenção básica, as melhorias e a ampliação nos cuidados de média e alta complexidades são tradução inequívoca dos avanços alcançados, a duras penas, nos anos recentes. Essas conquistas, entretanto, coexistem com a urgência em assegurar a universalidade e a integralidade do cuidado médico-sanitário, o que está diretamente vinculado a desafios históricos que vimos atravessando: (1) o subfinanciamento dos serviços públicos de saúde; (2) as condições de trabalho e educação dos profissionais do setor; (3) o investimento em pesquisa e produção; (4) o aprimoramento de mecanismos públicos de regulação sanitária, em especial do mercado crescente dos planos de saúde e da indústria de insumos e equipamentos médicos; (5) a qualificação da gestão e a adequação da oferta de serviços sanitários; e, sobretudo, (6) a promoção da saúde.

Concordando com as críticas em torno do tema de campanha - "por que tratar as pessoas sem mudar o que as torna doentes?” - propagado pela Organização Mundial da Saúde, não se trata de questionar o inquestionável. É imperativo o cuidado com saúde de todos. A defesa intransigente da Saúde, expressa na Constituição Brasileira, é um dever ético. Saúde é direito de todos e dever do Estado. Todos sabem, contudo, que Saúde inclui a garantia de cuidados médicos-sanitários, mas não se restringe a isso. Políticas de Saúde exigem ações concretas sobre seus determinantes sociais. Em que pesem toda a garra e os compromissos, não há como aprovar a regulamentação da Emenda Constitucional (EC) 29 sem, paralelamente, definir o modelo de desenvolvimento e a reforma política. O esforço de assegurar fontes sustentáveis e suficientes de financiamento da política de saúde integra o compromisso de articulação e concertação de prioridades no âmbito do Conselho Nacional de Saúde (CNS) e do Conselho de Desenvolvimento Econômico e Social (CDES). No Parlamento e no Executivo.

Em seu discurso de posse, a presidente Dilma Rousseff, reafirmando os avanços do governo que a antecedeu e reiterando sua vontade política, expressa que a luta mais obstinada do meu governo será pela erradicação da pobreza extrema e a criação de oportunidades para todos. Em continuidade, sublinha ser, portanto, tarefa indispensável uma ação renovadora, efetiva e integrada dos governos federal, estaduais e municipais, em particular nas áreas da saúde, da educação e da segurança, o que é vontade expressa das famílias e da população brasileira.

Hoje, mais do que nunca, a redução de iniquidades sociais implica a definição e a realização de políticas públicas intersetoriais.

Álvaro Matida

Centro de Relações Internacionais em Saúde, Fundação Oswaldo Cruz 